\title{
Cross-Sectional Analysis of Current State of Arts and Community Pharmacists' Attitudes toward Value-Added Pharmacy Services in Bulgaria
}

\author{
Stefan V. Balkanski ${ }^{1 *}$, Joana I. Simeonova ${ }^{2}$, Ivan G. Gitev ${ }^{1}$, Ilko N. Getov ${ }^{3}$ \\ ${ }^{1}$ Bulgarian Pharmaceutical Union, 36 Dragan Tsankov blvd., office B 602, floor 6, Sofia 1040 \\ ${ }^{2}$ Faculty of Public Health, Department of Social Medicine, Medical University - Sofia, 8 Byalo more str, 1527, Sofia \\ ${ }^{3}$ Faculty of Pharmacy, Department of Social Pharmacy, Medical University - Sofia, 2, Dunav street, Sofia 1000
}

DOI: $10.36348 /$ SJMPS.2019.v05i12.005

| Received: 02.12.2019| Accepted: 09.12.2019| Published: 11.12 .2019

*Corresponding author: Stefan Ventzislavov Balkanski

\section{Abstract}

Value-added pharmacy services (VAPS) are not connected with traditional pharmacy activities and do not include services, related to dispensing of medicines and professional consultation. A cross-sectional study that included pharmacists working in the community pharmacies in Bulgaria was carried-out. The pharmacists`attitudes toward VAPS and an implementation of remuneration were studied. The most commonly offered VAPS were blood pressure (BP) measuring with confirmation of $67.4 \%$ of the respondents and blood glucose (BG) measuring - $12.9 \%$, but $42.9 \%$ of the pharmacists were willing to provide the different VAPS. Most of the respondents (63.5\%) did not support the idea of implementation of a fee for BP measuring, but $53.7 \%$ considered it is necessary to charge a fee for BG measuring. VAPS are proven to have added value from societal, healthcare and economic point of view, but additional remuneration should be provided.

Keywords: Value-added pharmacy services, remuneration, pharmacists, community pharmacy, patient benefits

Copyright @ 2019: This is an open-access article distributed under the terms of the Creative Commons Attribution license which permits unrestricted use, distribution, and reproduction in any medium for non-commercial use (NonCommercial, or CC-BY-NC) provided the original author and source are credited.

\section{INTRODUCTION}

Value-added pharmacy services (VAPS) are additional to the traditional pharmacy activities that do not include dispensing of medicines and professional consultation. It is demonstrated that supplying VAPS can reduce the health system expenses, while inset added value to the pharmacists' work $[1,2]$. According to Porter "The value in healthcare is measured by the outcomes achieved, not the volume of services delivered" [3]. He also determines the value in healthcare as the ratio of the health outcomes achieved for the amount of money spent [4].

According to Moullin, offering value-added pharmacy services correlates to more effective medical treatment, improvement of health outcomes and an opportunity to carry out an overall assessment of the health of the patient [5].

The great administrative pressure that the pharmacist is exposed to is a growing topic of discussion and becomes very important. Pharmacists should be able to carry out much more activities other than dispensing medicinal products and other health goods. Typical examples are monitoring and optimization of the medicinal use, monitoring of the effects of therapy, activities related to additional services in the pharmacy, etc [6]. Pharmacists spend $68 \%$ of the working time dispensing medicinal products [7], with a possibility of even bigger percentages in Bulgaria. Roe [23] points out that the big pressure on pharmacists to dispense medicinal products as quickly as possible limits their time to discuss with the patient potential medicinal product interactions, adverse reactions and drug-related problems.

Developed countries show a clear trend and practice, in which the pharmacy actually has the functions of a health establishment, facilitating the access of the patient to health professionals. Over the recent years, there has been a rise in the amount of introduced pharmacy services in various countries around the world. Professional advice and additional services provided in pharmacies are becoming increasingly important [8-10].

A major goal of most professional pharmaceutical organizations is to change the attitude 
of the patients, the health insurance providers and the mindset of pharmacists themselves toward the pharmacy services offered in the pharmacy [11]. The aim is to point out to society that the pharmacist is a healthcare specialist who offers professional pharmaceutical services and consultations, that extend far beyond the current, more limited frameworks on dispensing medicinal products and food supplements [12].

The Joint document of International Pharmaceutical Federation (FIP) and World Health Organization (WHO) - Guidelines on Good Pharmacy Practice (GPP) requires that the objective of each element of pharmacy service is relevant to the patient, clearly defined and effectively communicated to everyone involved [13].

The aims of our study were:

1. To identify the value-added pharmacy services (VAPS) offered in Bulgarian pharmacies.

2. To identify the patients' needs to VAPS.

3. To clarify the pharmacists` attitudes toward VAPS.

\section{MATERIAL AND METHODS}

A cross-sectional study was carried-out in 2018. The study included pharmacists working in community pharmacies. A web-based questionnaire consisting of 15 questions was developed. Some questions obtained information about VAPS such as blood pressure and blood glucose measurement, vaccination in a pharmacy, etc. Needs of VAPS were identified and information about patients characteristics (age, chronic diseases, number of patients served per day, proportion of loyal patients) were obtained. The pharmacists attitudes toward VAPS and an implementation of remuneration were studied. The service fee is measured in local currency Bulgarian lev $(\mathrm{BGN})$. The fixed exchange rate is $1 \mathrm{EUR}=1.95583$ BGN.

Internal consistency of a scale was measured by Cronbach`s alpha. The overall Cronbach`s alpha $(\mathrm{N}=6)$ is 0.540 . There were no rejected items (if item deleted, the Cronbach`s alpha coefficients are from 0.210 to 0.520 ).

The questionnaire was submitted to all active members of the Bulgarian Pharmaceutical Union $(\mathrm{n}=5165)$. Two-hundred thirty-three questionnaires were filled (response rate of $4.5 \%$ ).

Data were processed by SPSS v.24.0. The number of cases falling in each range of the categories and the percentage were displayed. The variable "number of chronic diseases" was continuous and was described as median (Mdn), minimum and maximum values (Min, Max).

For statistical analysis, some variables were recoded. For example, variables "attitudes toward an implementation of charging fee for measuring a BP" and "attitudes...a BG" consisted 5 categories. Three of the categories, b) "I would charge a fee to EUR 2.565.11 ", c) "I would ... to EUR 5.62-7.67" and d) "I would... more than EUR 7.67" were combined into the new category "I would ... more than EUR 5.11". The category "I would ... more than EUR 5.11"of the variable "attitudes toward an implementation of charging a fee for injection and vaccination "was recoding and consisted one additional category "I would ... more than EUR 10.23“ besides the categories listed above.

Pearson's chi-square test was used. We assume the differences between groups are significant if the $\mathrm{p}$ value is less than or equal to 0.05 .

\section{RESULTS}

Distribution of the respondents by sociodemographic characteristics was shown in Table-1. Most of the respondents were female (214 or $74.7 \%$ ) which corresponds to the general distribution of pharmacists working in community pharmacy. 152 $(65.2 \%)$ were between 20 and 40 years of age. Eightysix $(36.9 \%)$ had professional experience of 5 years or less; $66(25.3 \%)$ had an experience in the range of 6-15 years.

Table-1: Characteristics of the pharmacists (Number, \%)

\begin{tabular}{|l|l|l|l|l|l|}
\hline Variable & Number $(\boldsymbol{\%})$ & Variable & Number $(\%)$ & Variable & Number (\%) \\
\hline Gender & & Age & & Professional & \\
Male & $59(25.3)$ & $20-30$ years & $93(39.9)$ & experience & $86(36.9)$ \\
Female & $174(74.7)$ & $31-40$ years & $59(25.3)$ & 5 years or less & $66(25.3)$ \\
Total & $233(100.0)$ & $41-50$ years & $38(16.3)$ & 6-15 years & $53(22.7)$ \\
& & $51-60$ years & $31(13.3)$ & $16-30$ years & $28(12.0)$ \\
& & Over 60 years & $12(5.2)$ & Over 30 years & $233(100.0)$ \\
\hline & & Total & $233(100.0)$ & Total & \\
\hline
\end{tabular}


Value-added pharmacy services (VAPS)

$121(51.9 \%)$ respondents worked in community pharmacies offering VAPS. The most commonly offered VAPS were BP measurement (157 or $67.4 \%$ ) and BG measurement (30 or $12.9 \%$ ).

$29.2 \%$ of the pharmacists used an automatic BP monitor; 49 (21\%) other used a commercial BP chair and rarely - a mechanical BP monitor (12.4\%) or a semiautomatic BP monitor (4.7\%).

\section{Patients' Needs of VAPS}

$49.8 \%$ of the community pharmacists dispensed multiple prescriptions mostly for children and adults (Table-2).
To identify the chronically ill patients, the pharmacists used information from "Prescription document of the chronically ill person". This document was processed in the pharmacy on the day the questionnaire was completed. Most common chronic diseases within the group of loyal patients were hypertension $(86.7 \%)$, cerebrovascular disease $(97.9 \%)$ and chronic obstructive pulmonary disease (COPD) $(54.9 \%)$.

Three or more chronic diseases were found in 163 patients (or 70\%). Average number of chronic diseases in the patients was three (Mdn, 1 Min, 5 Max).

Table-2: Characteristics of the pharmacy customers (Number, \%)

\begin{tabular}{|l|l|l|l|}
\hline Variable & Number (\%) & Variable & Number (\%) \\
\hline Patients & $116(49.8)$ & $\begin{array}{l}\text { Number of chronic diseases } \\
\text { Average number }\end{array}$ & $3(M d n)$ \\
Mostly adults & $3(1.3)$ & 1 disease & $20(8.6)$ \\
Mostly children & $114(48.9)$ & 2 diseases & $50(21.5)$ \\
Adults and children & $233(100.0)$ & $\geq 3$ diseases & $163(70.0)$ \\
Total & & Total & $233(100.0)$ \\
\hline Most common diseases* & & Patients served a day & \\
Hypertension & $202(86.7)$ & Less than 50 patients & $21(9.0)$ \\
Cerebrovascular disease & $228(97.9)$ & $50-200$ patients & $123(52.7)$ \\
COPD & $128(54.9)$ & $201-500$ patients & $64(27.5)$ \\
& & $501-1000$ patients & $19(8.2)$ \\
& & More than 1000 patients & $6(2.6)$ \\
& & Total & $233(100.0)$ \\
\hline Proportion of permanent customers & $20(8.6)$ & & \\
Less than 20\% & $45(19.3)$ & & \\
$21-40 \%$ & $76(32.6)$ & & \\
$41-60 \%$ & $71(30.5)$ & & \\
61-80\% & $21(9.0)$ & & \\
More than 80\% & $233(100.0)$ & & \\
Total & & \\
\hline
\end{tabular}

*Total number of diseases exceeds $233(100 \%)$ because most of the patients had several diseases.

$52.7 \%$ of the pharmacies served between 50 to 200 patients per day. According to $32.6 \%$ of pharmacists, the proportion of loyal patients in a month was in the range of $41-60 \%$. One third of the respondents thought that the proportion was between 61-80\% (Table-2).

\section{Pharmacists Attitudes toward VAPS}

$57,1 \%$ of the pharmacists were willing to provide VAPS different from BP and blood glucose measurement.

We studied the attitudes towards the implementation of a fee for VAPS.

$63.5 \%$ of pharmacists did not support the idea of implementation of a fee for BP measurement. $30.5 \%$ agreed to charging a fee not greater than EUR2.56.
Only $6 \%$ of the respondents agreed to charging a fee higher than EUR 2.56.

$125(53.7 \%)$ pharmacists considered charging a fee for BG measurement a necessity as opposed to 108 (46.4\%) respondents who did not. 103 (44.2\%) respondents agreed that fee should not be more than EUR 2.56. 22 (9.5\%) opted for a fee higher than EUR 2.56 .

For injection and/or vaccination, 107 (45.9\%) pharmacists would implement a fee between EUR 7.6710.23. $72(30.9 \%)$ thought that fees should be not more than EUR 2.56. About $18 \%$ expected a fee between EUR 2.56 and 5.11. Only $2(0.9 \%)$ were in favor of charging a fee higher than EUR 10.23. 
Relationships between VAPS and characteristics of the pharmacy customers the variables.

Of all 5 variables listed in Table-2, statistically significant associations with VAPS was found only for two of

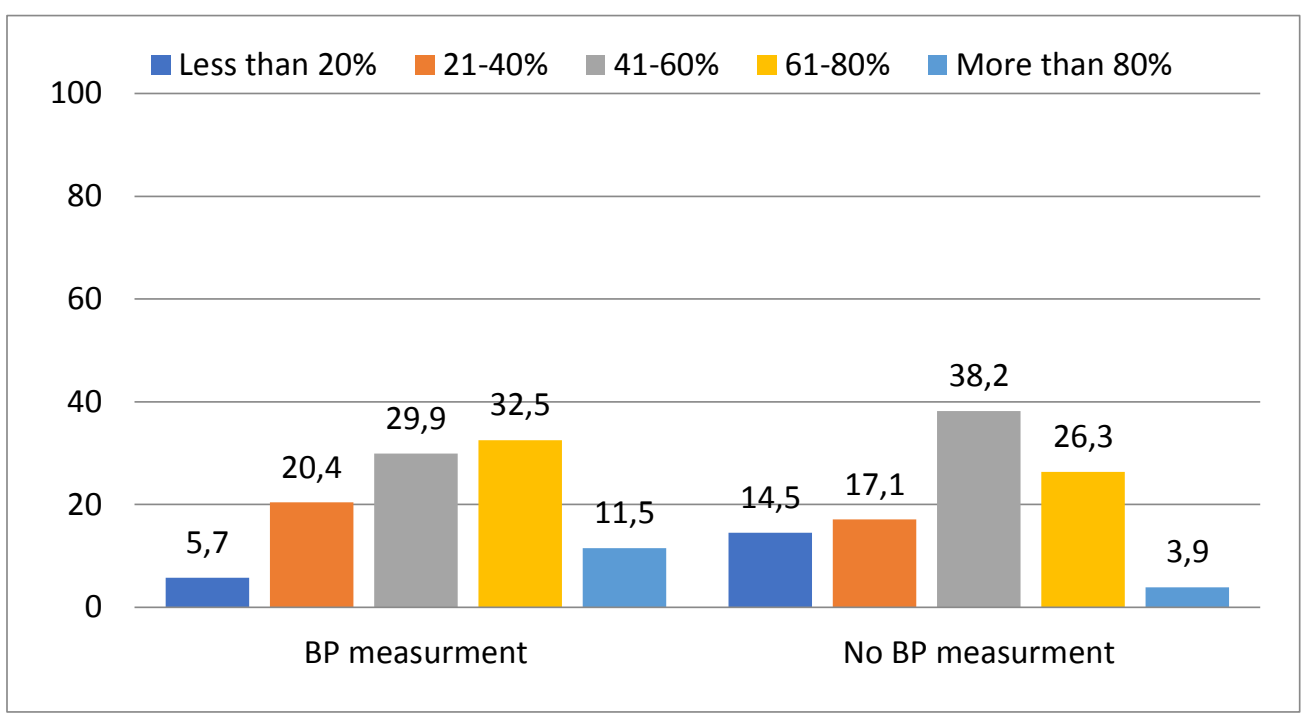

Fig-1: Correlation between regular patients and blood pressure measurement offered in the pharmacy $(\%)$

No correlation was found $(\mathrm{p}>0.05)$ for patients with polymorbidity (presence of three or more chronic diseases per person), hypertensive patients, patients with cerebrovascular disease, as well as adults visiting the pharmacies offering VAPS (BP and/or BG measurement). Plausible reason for such a result is that pharmacists working with comorbidity patients are mainly occupied with dispensing multiple medicinal products and do not have time to propose/offer additional services. Also, there were no statistically significant associations between the number of patients served per day and BP $(\mathrm{p}=0.921)$ and BG measurements $(\mathrm{p}=0.635)$.

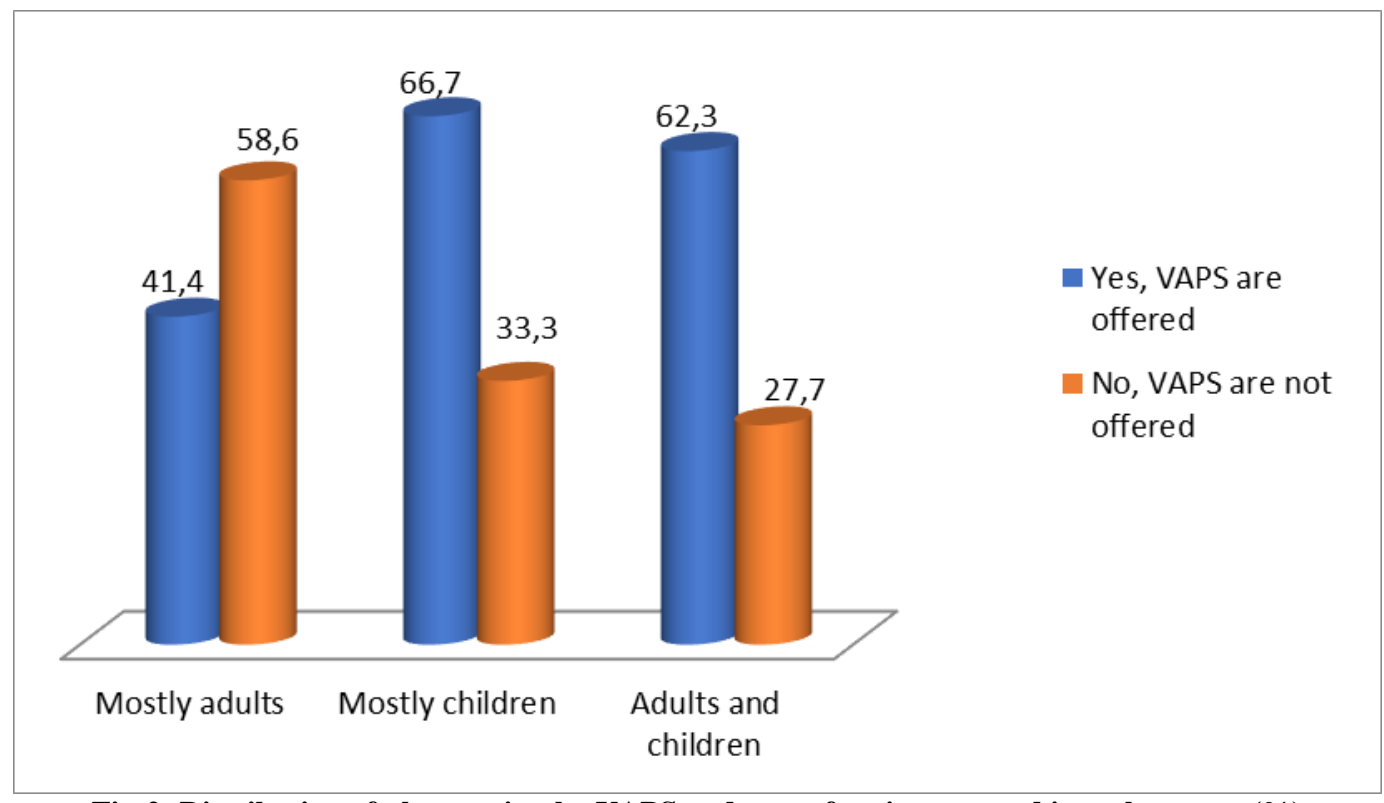

Fig-2: Distribution of pharmacists by VAPS and type of patients served in a pharmacy (\%)

As shown in Figure-2, pharmacies that served mostly children $(66.7 \%)$ or both children and adults $(62.3 \%)$, offered VAPS different from BP and BG measurements $\chi 2=10.327 ; \mathrm{df}=2 ; \mathrm{p}=0.006$.
Effect of pharmacist's age and patients served in pharmacies on pharmacist's attitudes towards VAPS

$39.2 \%$ of pharmacists unwilling to charge a fee for BP measurement, belonged to the 20-30 years age group, $23.6 \%$ belonged to the $31-40$ years age group. 
Almost $60 \%$ of the pharmacists aged 20-40 years were against implementation of a fee for BG measurement and only $21.3 \%$ of pharmacists aged over
50 years had the same opinion. The differences between the groups were not statistically significant $(\mathrm{p}=0.193)$.

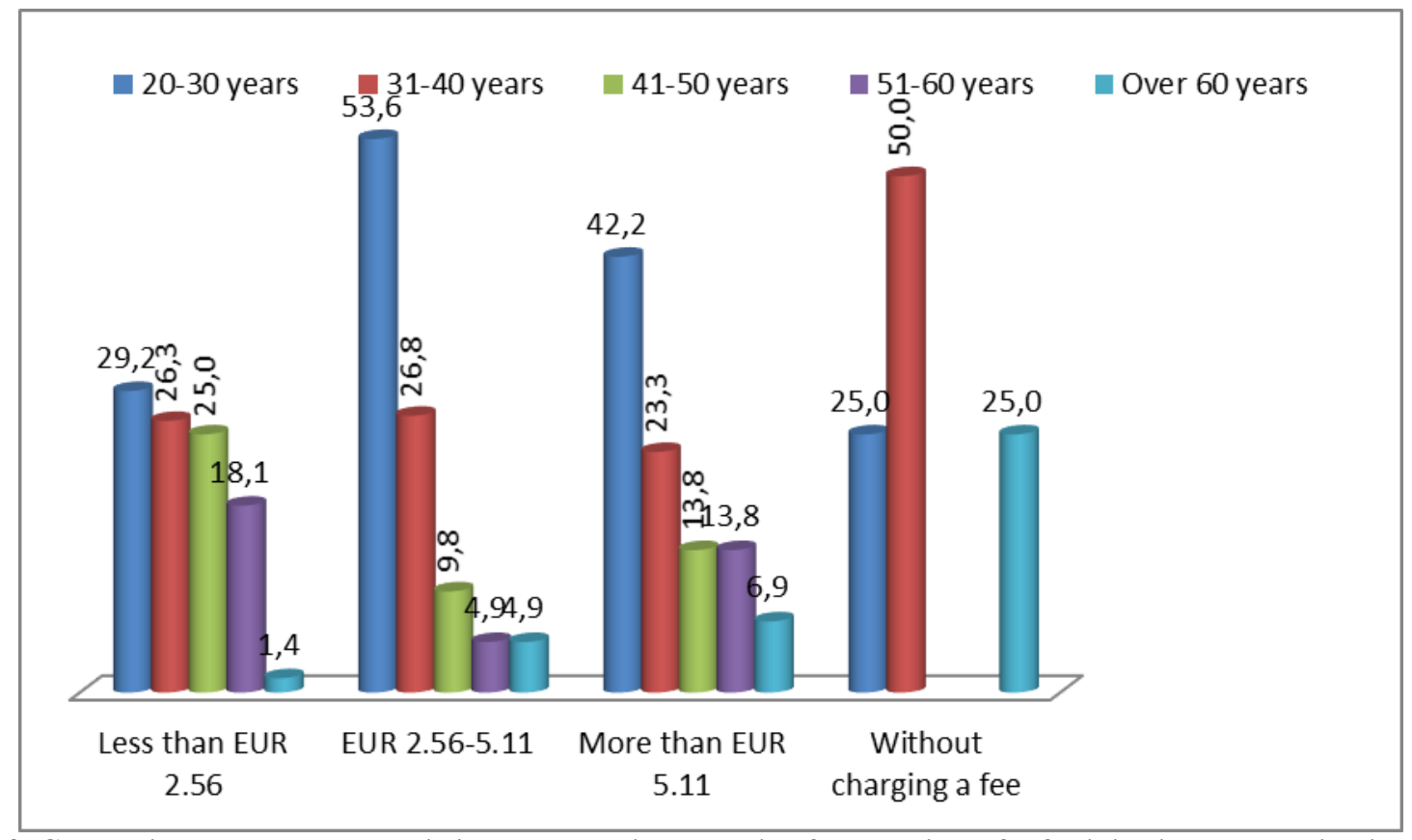

Fig-3: Correlation between pharmacist's age and their perception for charging a fee for injection and vaccination (\%)

Higher percentage of pharmacists willing to charge an injection and/or vaccination fee greater than EUR 5.11, belonged to the 20-30 years age group $(42.2 \%)$, while only $20.7 \%$ of them were older than 50 years. The differences between the groups were marginally significant $(\mathrm{p}=0.053)$ (Figure- 3 ).

Characteristics of the patients served in a pharmacy

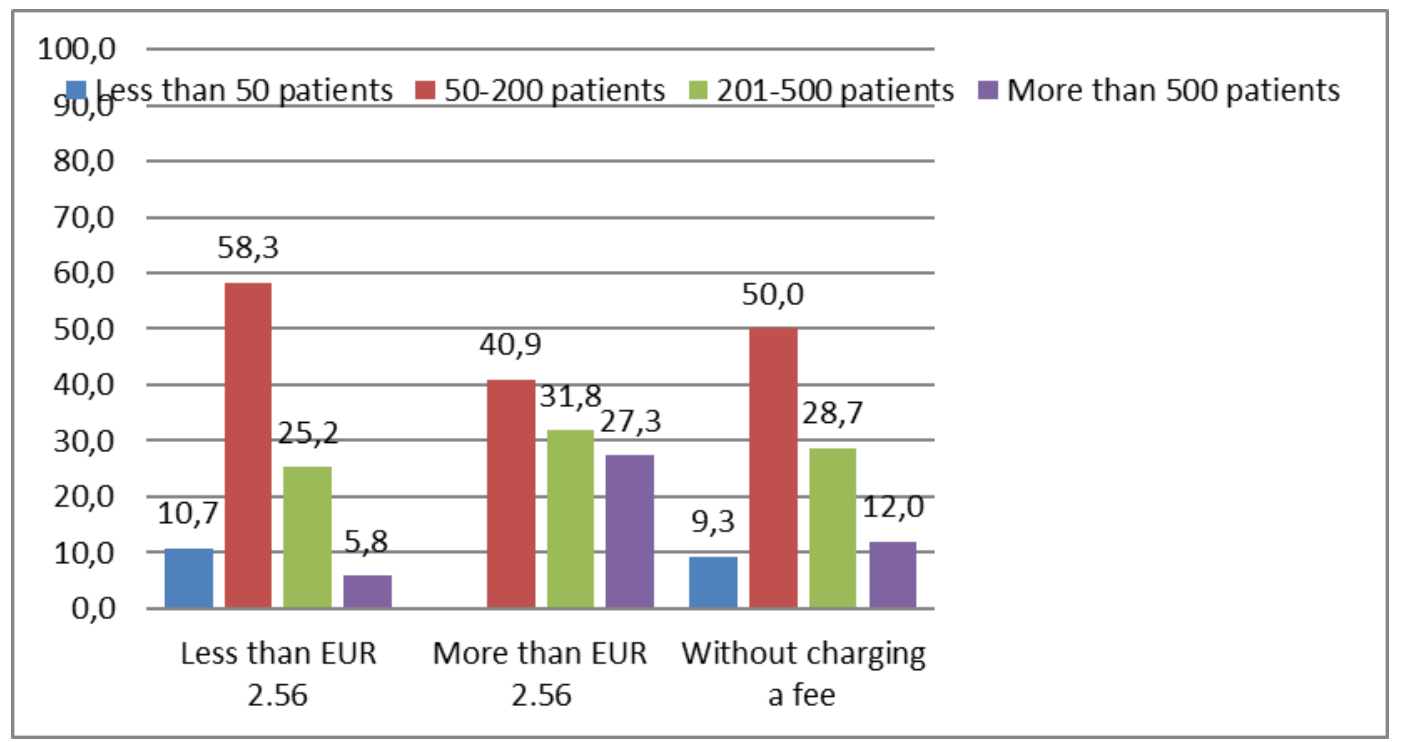

Fig-4: Correlation between pharmacist's age and their perception of charging a fee for injection and vaccination (\%)

With increase in the number of patients treated at a pharmacy, the percentage of pharmacists not willing to implement a blood glucose fee also increases: $9.3 \%$ in pharmacies with less than 50 patients per day to $52 \%$ in the pharmacies with more than 500 patients per day $\left(\chi^{2}=12.127 ; \mathrm{df}=6 ; \mathrm{p}=0.059\right)$.
There were no statistically significant differences between number of patients visiting a pharmacy per day and pharmacist's attitude toward implementation of remuneration for BP measurement $(\mathrm{p}=0.260)$. 
Pharmacists $(38.9 \%)$ who would charge a fee less than EUR 2.56 for injection and/or vaccination had more regular patients (41-60\% of total visiting patients). In $31.9 \%$ of the cases the proportion of regular patients ranged from 61-80\%. Higher fee (> EUR 5.11) was offered by pharmacies with regular patients in the ranges of $41-60 \%(34.5 \%)$ and $61-80 \%(26.7 \%)$. There were no statistically significant differences between the pharmacist's attitudes toward implementation of a fee for $\mathrm{BG}$ measurement and the proportion of regular patients in a pharmacy $(\mathrm{p}=0.861)$.

\section{DISCUSSION}

Providing additional services that suit the needs of the patients visiting the pharmacy can contribute for bigger success and better competitiveness. [14]

Various studies conclude that pharmacists are successful in providing high-quality care to their patients. Strong data indicate that evidence-based pharmaceutical care lead to improvement in health outcomes and cost-effective therapy of the patient. [15, 16]. A good example can be seen in the United Kingdom where since 2015 the public funds cover the expenses of seasonal influenza vaccinations of high-risk patients' groups in pharmacies. Previous studies show that this leads to an increase of the number of vaccinated patients [17], while ensuring lower costs for vaccinations in comparison with the traditional approaches [18]. In 2015 more than 500000 patients in the UK were vaccinated in the pharmacies, while not a single case of harm caused to a patient was reported [19]. In its annual report for 2018, the Pharmaceutical Group of the European Union [20] marks more successful examples for the integration of additional services in the pharmaceutical practice. In October 2017 in Belgium began the project "Family pharmacist", which aims to support patients with chronic diseases by preparing an individual medication plan. This plan is being updated with every change of the therapy and it can be sent electronically to the relevant medical specialist. For the first year, $80 \%$ of the pharmacies in the country were included in the project and 600000 patients have benefited from it, which is $5 \%$ of the population of the country [20].

For the successful development of VAPS, a reasonable payment should be provided. There are two options for payment - from the patients (out-of-pocket) or from the external payer (insurer or external body health institution, municipality, etc.). For this reason, pharmacies tend to aim at receiving remuneration for their services [21, 22].

\section{CONCLUSION}

Value-added pharmacy services are proven to have positive impact on the patient well-being, pharmacies welfare and economic survival and to the healthcare system as a whole. Most of the pharmacists working in community pharmacies in Bulgaria are willing to provide additional services and this is expected to have a very positive perception by the patients. At the same time, such additional services in the pharmacy will have added value from societal, healthcare and economic point of view, but additional remuneration should be provided.

\section{REFERENCES}

1. Saha, S., Gerdtham, U. G., Johansson, P., Saha, S., Gerdtham, U. G., \& Johansson, P. (2010). Economic Evaluation of Lifestyle Interventions for Preventing Diabetes and Cardiovascular Diseases. International Journal Environmental Research Public Health, 7(8):3150-3195.

2. Painter, J. T., Gressler, L., Kathe, N., Slabaugh, S. L., \& Blumenschein, K. (2018). Consumer willingness to pay for pharmacy services: An updated review of the literature. Research in Social and Administrative Pharmacy, 14(12), 1091-1105.

3. Porter, M. E. (2010). What is value in health care. $N$ Engl J Med, 363(26), 2477-2481.

4. Porter, M. (2006). Redefining Health Care: Creating Value-Based Competition on Results.

5. Moullin, J. C., Sabater-Hernández, D., FernandezLlimos, F., \& Benrimoj, S. I. (2013). Defining professional pharmacy services in community pharmacy. Res Soc Adm. Pharm, 9(6):989-995.

6. Ai, A. L., Carretta, H., Beitsch, L. M., Watson, L., Munn, J., \& Mehriary, S. (2014). Medication Therapy Management Programs: Promises and Pitfalls. Journal Manag Care Pharm, 20(12):1162-1182.

7. Gaither, C. A., Schommer, J. C., Doucette, W. R., Kreling, D. H., \& Mott, D. A. (2015). Final report of the 2014 national sample survey of the pharmacist workforce to determine contemporary demographic practice characteristics and quality of work-life. American Association of Colleges of Pharmacy: Arlington, VA, USA.

8. McDonald, R., Cheraghi-Sohi, S., Sanders, C., \& Ashcroft, D. (2010). Professional status in a changing world: The case of medicines use reviews in English community pharmacy. Soc Sci Med, 71(3), 451-458.

9. Scott, A., Bond, C., Inch, J., \& Grant, A. (2007). Preferences of Community Pharmacists for Extended Roles in Primary Care. Pharmacoeconomics, 25(9), 783-792.

10. Cooksey, J. A., Knapp, K. K., Walton, S. M., \& Cultice, J. M. (2002). Challenges to the pharmacist profession from escalating pharmaceutical demand. Health affairs, 21(5), 182-188.

11. Caamaño, F., Álvarez, R., \& Khoury, M. (2008). The community pharmacists and their practice as health care providers. Gaceta sanitaria, 22, 385385 . 
12. Harrison J., Scahill, S., \& Sheridan, J. (2012). New Zealand pharmacists' alignment with their professional body's vision for the future. Res Soc Adm Pharm, 8(1):17-35.

13. FIP/WHO. (2011). Guidelines on Good Pharmacy Practice: Standards for Quality of Pharmacy Services. WHO Tech. Rep, 961:310-323.

14. Richardson, E., \& Pollock, A. M. (2010). Community pharmacy: moving from dispensing to diagnosis and treatment. BMJ, 340, 2298.

15. Santschi V., Chiolero, A., Burnand, B., Colosimo, A. L., \& Paradis, G. (2011). Impact of Pharmacist Care in the Management of Cardiovascular Disease Risk Factors: a systematic review and meta-analysis of randomized trials. Arch Intern Med, 171(16):1441.

16. Al-Quteimat, O. M., and Amer A. M. (2016). Evidence-based pharmaceutical care: The next chapter in pharmacy practice. Saudi Pharm Journal, 24(4):447-451.

17. Warner, J. G., Portlock, J., Smith, J., \& Rutter, P. (2013). Increasing seasonal influenza vaccination uptake using community pharmacies: experience from the I sle of $\mathrm{W}$ ight, E ngland. International Journal of Pharmacy Practice, 21(6), 362-367.

18. Atkins, K., van Hoek, A. J., Watson, C., Baguelin, M., Choga, L., Patel, A., ... \& Griffiths, U. (2016). Seasonal influenza vaccination delivery through community pharmacists in England: evaluation of the London pilot. BMJ open, 6(2), e009739.

19. Wright, D. (2016). A rapid review of evidence regarding clinical services commissioned from community pharmacies. 1-50.

20. PGEU. (2018). PGEU Annual Report 2018.

21. Hogue, M. D. (2002). The pharmacist's guide to compensation for patient-care services. Amer Pharmacists Assn.

22. Farris, K. B., Fernandez-Llimos, F., \& Benrimoj, S. I. (2005). Pharmaceutical care in community pharmacies: practice and research from around the world. Ann Pharmacother. 39(9), 1539-1541.

23. Roe, S., Menictas, C., \& Skyllas-Kazacos, M. (2016). A high energy density vanadium redox flow battery with $3 \mathrm{M}$ vanadium electrolyte. Journal of The Electrochemical Society, 163(1), A5023-A5028. 